Th G104 02

\title{
Establishing 3D Numerical Reservoir Analogues - Modelling the Formation of Sand Bodies in Deltaic Environments
}

\author{
H. van der Vegt* (Delft University of Technology), J.E.A. Storms (Delft \\ University of Technology) \& D.J.R. Walstra (Deltares)
}

\section{SUMMARY}

The assessment and production of hydrocarbon resources incorporates geological models created from core and wireline well data, as well as seismic data. This data is spatially discrete but is used create a spatially continuous model. However, the heterogeneity within depositional environments is on a smaller spatial scale than the available data resolution. The field data is therefore supplemented with relevant analogue data, often from deposits which differ in various aspects from the actual reservoir being assessed. To improve the correlation between analogues and the reservoir being studied, it is proposed that 3D numerical analogues are used in addition to the current outcrop analogues. These 3D numerical analogues can be created through process based numerical modelling and can more closely match the conditions of the reservoir being studied. In this presentation we propose a workflow to create and implement 3D numerical outcrops. We go on to show an initial stage of a proof of concept for the workflow. It is shown that using the software Delf3D, it is possible to simulate the sand bodies found in deltaic deposits, which can later act as hydrocarbon reservoirs. 


\section{Amsterdam ' 14}

\section{Introduction}

During the assessment and production of hydrocarbon resources, access to accurate geological reservoir models is essential. During assessment, geological reservoir models are used to determine the economic potential of a deposit. During production the model informs the development plan to extract the hydrocarbons in the most efficient and economical way. The geological models are typically created from core and wireline well data, as well as seismic data. These measurements are spatially discrete yet are used to create a continuous model using stochastic techniques such as multipoint statistics or object based techniques (Holden, et al. 1998; Caers and Zhang 2004). The heterogeneity within depositional environments, e.g. in deltaic environments, will be on a smaller spatial scale than the well spacing and seismic resolution (Moore, et al. 2012; Ravenne, et al. 1989).

In addition to this reservoir data, relevant field analogues are identified and referred to for model optimisation. Although these analogues provide additional information (e.g. channel distributions, channel geometries and geological facies distributions and geological features) the information is also limited by data availability at the outcrop. Additionally, available analogues often differ in various aspects from the actual reservoir being assessed (Alexander 1993). For example the environment, geometry and rate of deposition of an analogue may correspond with the reservoir deposit being studied, but the sediment grain-size distribution may differ. It is important to clearly understand what impact such a difference has on the deposition's geometry and reservoir properties.

\section{Theory and Method}

Process based numerical modelling can be implemented to study the effect of different sets of boundary conditions and physical processes definitions within the known depositional environment in four dimensions. E.g. the effect of sediment grain size distribution on the shape and size of the resultant mouth bars can be studied. Models for this study are created using the Delft3D software package (Roelvink and Van Banning 1995; Lesser, et al. 2004) which applies the finite difference method to numerically solve the Navier Stokes equations on a curvilinear grid. The software simulates fluid flow, sediment transport as well as morphological changes.

The obtained model results can be used as a 3D numerical analogues. It is possible to match the input values for a set of 3D numerical analogues to the proposed or assumed conditions of deposition for a specific reservoir of interest. This provides a flexible approach to generating reservoir analogues. A workflow for the creation and implementation of 3D numerical analogues to optimise geological reservoir models should include:

- Model input: A selection procedure for identifying appropriate boundary conditions based on geometry, physical processes and sediment properties.

- Model execution: Access to model results based on these boundary conditions either through a library of pre-existing models or the simple generation of custom models.

- Results application: Application of model output as a 3D numerical analogue to optimise geological reservoir models.

A proof of concept is required for the development of such a workflow. This proof of concept will be implemented on fluvio-deltaic depositional environment. The application of Delft3D to delta formation has been extensively described in the previous studies (e.g. Geleynse, et al. 2010; Geleynse, et al. 2011; Edmonds and Slingerland 2009)

For deltaic hydrocarbon reservoirs, the formation and 3D geometry of large sand bodies, which will later form connected porous sandstones with good reservoir properties, are of key importance (Tye, et al. 1999). The work presented here will be the first step towards a proof of concept.

Sand bodies in deltaic depositional environments can originate from the formation of bars and levees as well as the infill and migration of channels. However the total sand body extent will depend on the lateral connectivity between these sand rich features (Ravenne, et al. 1989). Past research into details 


\section{Amsterdam |'14}

of deltaic features have been conducted in the field (Ashworth, et al. 2011), experimentally (Rowland, Dietrich and Stacey 2010) as well as numerically (Chatanantavet, Lamb and Nittrouer 2012; Nardin, et al. 2013; Leonardi, et al. 2013; Edmonds and Slingerland, 2007; Edmonds, et al. 2010). Previous work on mouth bars, for example, includes their formation of river dominated delta networks (Edmonds and Slingerland, 2007) but there has also been studies focussed on sub-aqueous levee formation (Rowland, Dietrich and Stacey 2010). The effects of tides (Leonardi, et al. 2013) and waves (Nardin, et al. 2013) on the formation of deltaic mouth bars has been investigated. There has also been work considering the effect of different sediment types on delta deposits (Edmonds, et al. 2010), but this study did not look at the influence on 3 dimensional distribution of facies in the resultant system. In braided river systems, it has been shown that there is so little variation between channel fill and bar deposits that they are in practice indistinguishable (Ashworth, et al. 2011). The study does not explore whether this is also the case for delta systems and a similar study on deltaic deposits could be conducted. Chatanantavet, et al (2012) looked at the influence of variable river discharge on deposition in the river delta and found that it can have strong influences on the stratigraphy. Much work has been done on distributary channel networks in rivers and deltas (Kleinhans, et al. 2013), but the focus of these studies have not been connectivity of sandy deposits.

As an extension to the existing body of knowledge, a set of 3D numerical outcrops are created to study the continuous and time varying definitions of a range of individual physical properties and boundary conditions as well as their combined effect. Physical properties and boundary condition investigated incudes e.g. variations in sediment distributions, specific sediment properties such as settling velocity, surface roughness definitions, long term and short term (tidal) sea level changes and river input flow rates. The influence of these changes on the sand bodies are investigated by looking at e.g. vertical and lateral extent of the body, channel properties and facies distributions. Model stability under these sets of variables are also explored through investigation of geometric scales, which shows the flexibility of the method.

\section{Example: Variation of mass-median-diameter of the modelled sand fraction}

Figures 1 and Figure 2 shows the fraction of sand present in various geometric locations for two different models. The two example models differ only in the mass-median-diameter (D50 value) of the sand sediment fraction. In one model the sand is defined to have a D50 value of $150 \mu \mathrm{m}$ while the other has a value of $250 \mu \mathrm{m}$. It can be seen that the resultant 3D geometric shapes of the sand deposits vary considerably.
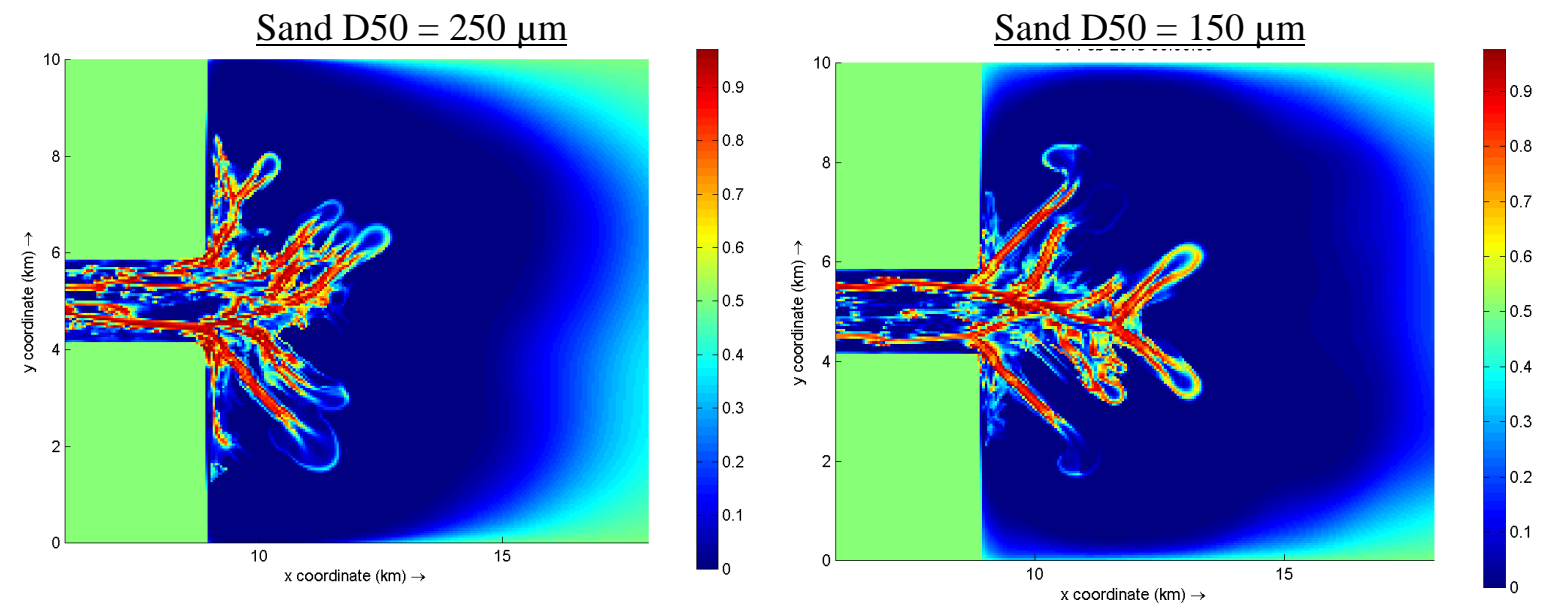

Figure 1 Fraction of sand in the top sediment layer for two models of delta formation. Models differ only in D50 grain size value of the sand fractions. 


\section{Amsterdam ' 14}
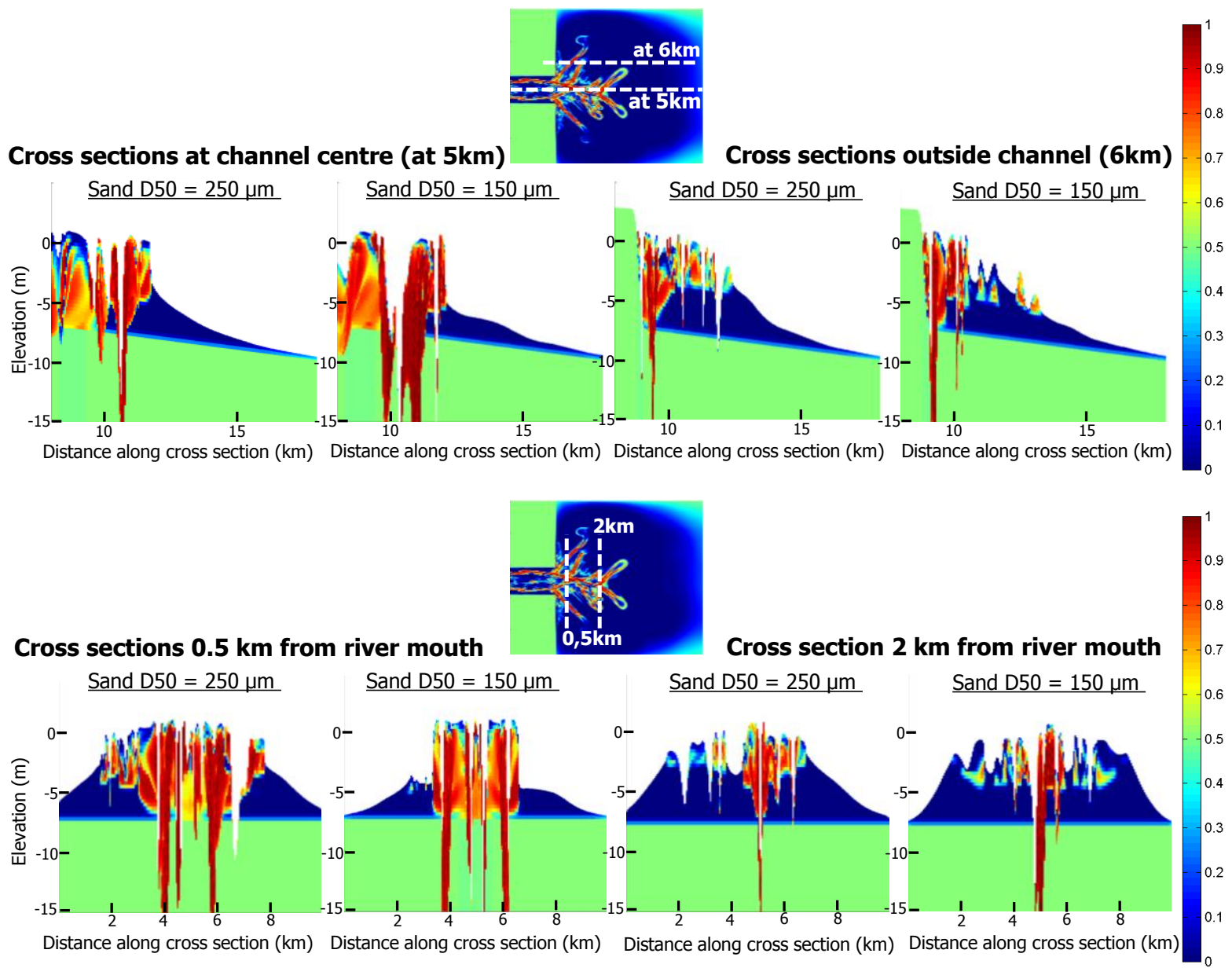

Figure 2: Fraction of sand in various cross sections for two models of delta formation. Models differ only in D50 grain size value of the sand fractions.

\section{Conclusions}

Delft 3D can, under the appropriate boundary conditions, simulate the sand bodies found in deltaic deposits which can also act as hydrocarbon reservoirs. These results only address the first step in establishing a workflow for implementation of 3D numerical reservoir analogues. Work will continue on:

- The selection procedure of appropriate boundary conditions for each reservoir, also including wave influence or sediment compaction on final model results and stability.

- Investigations on longer timescales showing typical high stand and low stand delta formation

- Implementing the 3D numerical analogue to optimise existing reservoir models and comparing the old and new reservoir models by analysing their performance in terms of production curves, OIIP, connectivity etc

- Automated extraction of relevant properties and lithofacies classification based on bedforms.

\section{Bibliography}

Alexander, J. "A discussion on the use of analogues for reservoir geology." Geological Society, London, Special Publications 69.1, 1993: 175-194.

Ashworth, P. J., et al. "Evolution and sedimentology of a channel fill in the sandy braided South Saskatchewan River and its comparison to the deposits of an adjacent compound bar." Sedimentology, 2011: 1860-1883. 


\section{Amsterdam ' 14}

Caers, J., and T. Zhang. "Multiple-point geostatistics: a quantitative vehicle for integrating geologic analogs into multiple reservoir models." AAPG Mem, 2004: 383-394.

Chatanantavet, P., M. P. Lamb, and J. A. Nittrouer. "Backwater controls of avulsion location on deltas." Geophysical Research Letters, 2012.

Edmonds, D. A., and R. L. Slingerland. "Mechanics of river mouth bar formation: Implications for the morphodynamics of delta distributary networks." Journal of Geophysical Research: Earth Surface, 2007.

Edmonds, D. A., and R. L. Slingerland. "Significant effect of sediment cohesion on delta morphology." Nature Geoscience, 2009: 105-109.

Edmonds, D. A., R. Slingerland, J. Best, Parsons D., and N. Smith. "Response of river-dominated delta channel networks to permanent changes in river discharge." Geophysical Research Letters, 2010.

Geleynse, N., J. E. A. Storms, M. J. F. Stive, H. R. A. Jagers, and D. J. R. Walstra. "Modeling of a mixed-load fluvio-deltaic system." Geophysical Research Letters, 2010.

Geleynse, N., J. E. Storms, D. J. R. Walstra, H. R. Jagers, Z. B. Wang, and M. J. Stive. "Controls on river delta formation; insights from numerical modelling." Earth and Planetary Science Letters, 2011: 217-226.

Holden, L., R. Hauge, Ø. Skare, and A. \& Skorstad. "Modeling of fluvial reservoirs with object models." Mathematical Geology, 1998: 473-496.

Kleinhans, M. G., R. I. Ferguson, S. N. Lane, \& Hardy, and R. J. "Splitting rivers at their seams: bifurcations and avulsion." Earth Surface Processes and Landforms, 2013: 47-61.

Leonardi, N., A. Canestrelli, T. Sun, and S Fagherazzi. "Effect of tides on mouth bar morphology and hydrodynamics." Journal of Geophysical Research: Oceans, 2013: 4169-4183.

Lesser, G.R., J.A. Roelvink, J.A.T.M. van Kester, and G.S. Stelling. "Development and validation of a three-dimensional morphological model." Coastal engineering, 2004: 883-915.

Moore, J., A. Taylor, C. Johnson, B. D. Ritts, and R. \& Archer. "Facies Analysis, Reservoir Characterization, and LIDAR Modeling of an Eocene Lacustrine Delta, Green River Formation, Southwest Uinta Basin, Utah." Lacustrine sandstone reservoirs and hydrocarbon systems: AAPG Memoir, 2012: 183-208.

Nardin, W., G. Mariotti, D. A. Edmonds, R. Guercio, and S Fagherazzi. "Growth of river mouth bars in sheltered bays in the presence of frontal waves." Journal of Geophysical Research: Earth Surface, 2013.

Ravenne, C., R. Eschard, Y. Mathieu, L. Montadert, J. L. Rudkiewicz, and A. \& Galli. "Heterogeneities and geometry of sedimentary bodies in a fluvio-deltaic reservoir." SPE Formation Evaluation 4.2, 1989.

Roelvink, J. A., and G. K. F. M. Van Banning. "Design and development of DELFT3D and application to coastal morphodynamics." Oceanographic Literature Review 42.11, 1995.

Rowland, J. C., W. E. Dietrich, and M. T Stacey. "Morphodynamics of subaqueous levee formation: Insights into river mouth morphologies arising from experiments." Journal of Geophysical Research: Earth Surface, 2010.

Tye, R. S., et al. "Geology and stratigraphy of fluvio-deltaic deposits in the Ivishak Formation: applications for development of Prudhoe Bay Field, Alaska." AAPG bulletin 83.10, 1999: 1588-1623. 